\title{
Prevalence of CCR5-tropic HIV-I among treatment-experienced individuals in South Africa infected with Clade $\mathbf{C}$ virus S Eng*1, I Sanne ${ }^{2}$, S Badal-Faesen ${ }^{2}$, R Wood ${ }^{3}$, N Rajicic ${ }^{1}$ and R Tressler ${ }^{1}$
}

\author{
Address: ${ }^{1}$ Pfizer Inc, New York, USA, ${ }^{2}$ University of the Witwatersrand, Johannesburg, South Africa and ${ }^{3}$ University of Cape Town, Cape Town, \\ South Africa \\ * Corresponding author
}

\author{
from Ninth International Congress on Drug Therapy in HIV Infection \\ Glasgow, UK. 9-13 November 2008 \\ Published: 10 November 2008 \\ Journal of the International AIDS Society 2008, I I(SuppI I):PI 98 doi:I0.II86/I758-2652-II-SI-PI 98
}

This abstract is available from: http://www.jiasociety.org/content/II/SI/PI 98

(C) 2008 Eng et al; licensee BioMed Central Ltd.

\section{Purpose of the study}

HIV-1 enters target cells by binding to the CD4 molecule and a co-receptor (CCR5 [R5] and/or CXCR4 [X4]). HIV1 may be classified as R5-tropic, X4-tropic, or dual/mixed (D/M) tropic depending on the co-receptor(s) used. Little is known about the prevalence of R5-tropic HIV-1 in regions of the world where non-clade $\mathrm{B}$ virus predominates. The objectives of this study were to determine the prevalence of R5-tropic HIV-1 amongst treatment-experienced (TE) individuals in South Africa infected with Clade $\mathrm{C}$ virus (the predominant Clade in South Africa) and to ascertain variables associated with $\mathrm{R} 5$ tropism.

\section{Methods}

At a single study visit, in this cross-sectional study conducted at three sites in South Africa, a brief questionnaire elicited information on demographics, HIV clinical history, and antiretroviral regimens. Blood was drawn from subjects and analyzed for CD4 cell count, HIV-1 RNA load (VL), and HIV-1 genotype to ascertain clade. Clade C samples with a VL of $>1,000$ copies $/ \mathrm{mL}$ were tested for tropism via the original phenotypic Trofile ${ }^{\mathrm{TM}}$ assay.

\section{Summary of results}

Of the 353 subjects recruited for this study, 294 (84.2\%) had a VL of $>1,000$ copies/mL; 276 (93.9\%) of these were infected with Clade C HIV-1. Tropism results were obtained for 206 (74.6\%) subjects with Clade C HIV-1. Mean age at study entry was 37 years; $40.8 \%$ of subjects were male, and the majority ( $97.6 \%$ ) were of African race/ ethnicity. Most (98.1\%) subjects reported a heterosexual mode of HIV-1 transmission. Mean VL was 122,978 copies/mL and mean CD4 cell count was 208 cells/ $\mu \mathrm{L}$. R5, D/ $\mathrm{M}$ and X4-tropic HIV-1 was present in 146 (70.9\%), 52 $(25.2 \%)$ and 8 (3.9\%) of TE subjects, respectively. A multivariate logistic model was fitted including age, sex, CD4 cell count, VL, time since HIV diagnosis, and mode of HIV transmission. Backward selection from a saturated model with all two-way interactions yielded three variables significantly associated with $\mathrm{R} 5$ tropism: age, $\mathrm{VL}$, and $\mathrm{CD} 4$ cell count.

\section{Conclusion}

R5-tropic HIV-1 was the predominant variant detected in this TE South African population infected with Clade C HIV-1. In a multivariate model, older age, higher CD4 cell count, and higher VL were all associated with the presence of R5 co-receptor usage. 